\title{
Oversampled Modal Approach of a Turbocharger Rotor from the Experimental Lateral Vibrations
}

\author{
Luis Alvaro Montoya Santiyanes, Eloy Edmundo Rodríguez Vázquez, Helen Janeth \\ Zúñiga Orozco and Israel Mejía Alonso \\ Centro de Ingeniería y Desarrollo Industrial (CIDESI), Av. Playa Pie de la Cuesta No. 702. Desarrollo San Pablo. \\ Querétaro, Qro. Mexico, 76125.
}

(Received 9 February 2018; accepted 6 June 2018)

The elements of rotors have inherent characteristics as geometry and material composition, which causes natural vibrations at frequencies that, due to the rotor unbalance, may coincide with the harmonics of the shaft speed, increasing stress and the probability of fractures even in transient conditions. Therefore, in this work, a theoreticalexperimental hybrid method for calculating the natural frequencies and the mode shapes, at rest and non-supported conditions, of a turbocharger rotor is proposed. Firstly, a discrete model of low number of degrees of freedom is considered, and from an oversampled modal approach (OSMA) based on the axial oversampling, sectioning and coupling of the rotor, it is possible to use the oversampled mode shapes to increase the degrees of freedom of the system without major complications in the model. This spatial oversampling criterion is based on the NyquistShannon theorem, and it is used to reduce the error in the estimates of the natural frequencies and to get a first approximation of the mode shapes. The natural frequencies were estimated by the transfer matrix method (TMM) and finite element method (FEM) in order to compare the proposed model results with well-founded numerical methods.

\section{INTRODUCTION}

Currently, turbomachinery requires higher speed and greater efficiency, which demands designs with very low clearances, ${ }^{1,2}$ so there is massive interest in acquiring, analysing, and quantifying vibration parameters for improving reliability, life, quality control, productivity, and safety against catastrophic failure. $^{3}$ Rotors in operation may experience vibration due to high levels of stress, temperature, aerodynamic, and centrifugal forces, as well as starts and stops of machinery. ${ }^{4}$ The rotor unbalance causes the natural frequencies of the elements be excited by the harmonics of the shaft speed, increasing stress and the probability of fractures even in transient conditions, ${ }^{5}$ and the mode shapes help to identify if the motion is near the bearing supports, which could affect the rotor critical speeds. ${ }^{6}$ In this lies the importance of studying the dynamic conditions of rotating systems, such as modal frequencies, as they can help to detect failures. ${ }^{7}$ The experimental modal analysis uses measurement of frequency response functions and then estimates modal characteristics (natural frequencies, mode shapes, damping factors) from the measured data. ${ }^{8}$ Force transducers, accelerometers, data acquisition systems, and signal amplifiers are used to estimate the frequency response functions. ${ }^{9}$ Modal characteristics are inherent in a dynamic system, which can be determined by their physical properties such as mass, stiffness and damping, and spatial distributions of these. ${ }^{10}$

Among the most common methods to estimate the modal characteristics of the rotors are the finite element method (FEM) and the transfer matrix method (TMM). ${ }^{11}$ Y. Zhang and $\mathrm{Z}$. Du obtained the natural frequencies of a gas turbine rotor experimentally and found that each order of natural frequency increases with contact stresses. They showed that using these frequencies and the FEM software SAMCEF Field, the effect of the contact stiffness can be obtained. ${ }^{12}$ The natural frequen- cies of a rotor vary with many factors such as the structure, the supports and the accuracy of the model, so it becomes complex to get a good prediction. ${ }^{13} \mathrm{G}$. Xu et al. determined the natural frequencies and mode shapes of a rotor using finite element models in ANSYS considering the bearings stiffness and damping. ${ }^{13}$ They noted that the mode shapes define where the mass unbalance forces have to be positioned, and that using different bearings, the natural frequencies and critical speeds can be controlled. M. Lu et al. indicate that each order of natural frequency of a gas turbine rotor increases with rod preloads, because the stiffness changes. ${ }^{14}$ These preloads have a significant effect on the deflections and stresses, which modifies the modal analysis. ${ }^{15}$ H. Taplak and M. Parlak made a dynamical analysis of a gas turbine rotor using the Dynrot program with code based on the FEM, ${ }^{16}$ they found the system has an unstable behaviour when it is near to the critical speeds, and that small imbalance values do not affect the behaviour but decrease the critical speeds. N. D. Pagar and S. H. Gawande obtained the natural frequencies and mode shapes of a rotor shaft using ANSYS and validated the results with an experimental test using FFT (Fast Fourier Transform) analyser. If the system is modified with mountings and accessories, then stiffness increases and therefore the natural frequency. ${ }^{17} \mathrm{R}$. Fegade et al. presented a harmonic analysis to identify frequency of a system with different configuration of bearings using ANSYS. ${ }^{18}$ They used the unbalance of the rotor as excitation to perform the analysis and mentioned that rotating critical speeds are associated with high vibration amplitude. In this case, a system with symmetric orthotropic bearings gave the less critical speed, so this kind of analysis is important to know the vibration amplitude response for minimizing the noise of the rotor. I. Ramirez Vargas et al. used a finite element model of a Jeffcott rotor in ANSYS, approaching the stiffness and damping coefficients of hydrodynamic bearings. ${ }^{19}$ It was performed 


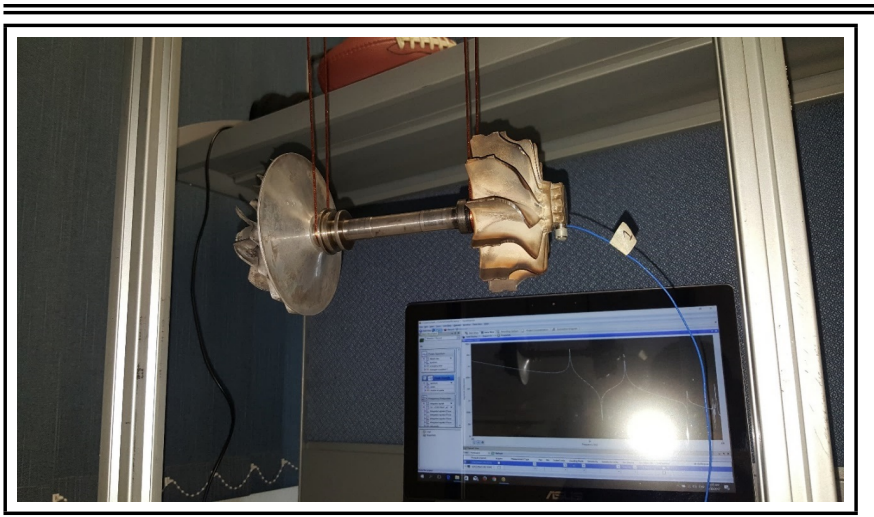

Figure 1. Turbocharger rotor.

a harmonic analysis to determine the vibrational response in steady and transient state. The transient analysis showed the required excitation of the rotor to go through a natural frequency. The modal analysis reveals if any natural frequencies will be near the operating speed and if it is necessary to carry out a harmonic analysis.

The TMM solves dynamic problems in the frequency domain, which makes itself suitable to analyse the steady state responses of rotor-bearing systems with the advantages of little memory requirement and satisfactory accuracy, ${ }^{20-22}$ as well as simple programming and adaptability, ${ }^{23,24}$ regardless of the subdivisions required to analyse the eigenvalues and eigenvectors of a whole structure. ${ }^{25,26}$ The TMM has been widely applied to structural mechanics, rotor dynamics, and multibody system dynamics. Thus, TMM could provide a powerful means for efficient dynamics modeling. ${ }^{27}$ The state variables for FEM are displacements, velocities, and accelerations, but for the TMM are displacements, slopes, bending moments, and shearing forces. Therefore, the TMM would be more effective than FEM. ${ }^{28}$ E. Al-Bahkali and M. ElMadany used the TMM to develop a graphical interface in MATLAB, to obtain the critical speed and the response to the imbalance of rotating machinery. ${ }^{29}$ The estimation by the TMM and the experiments are close enough for a rotor with two disks and two simple supports. J. W. Zu and Z. Ji proposed an improved TMM for rotorbearing systems with nonlinear bearings, which demonstrate the influence of nonlinear bearings on the dynamic response of the system. ${ }^{30} \mathrm{O}$. Ghasemalizadeh et al. identified the natural frequencies of a rotor with a TMM, which considers the width of the discs and bearings. ${ }^{31}$ They determined with this consideration that the fundamental frequency increases and the amplitude of vibration decreases. The TMM can also be modified to consider contact effects between components of the rotors and thus reduce the error in the estimates of the critical speeds with respect to the experimental measurements. The TMM has a higher rate of computation of eigenvalues and greater numerical stability. ${ }^{32-34}$ Studies have also been reported that combine the analysis by FEM and TMM. B. Rong et al. developed a modified method of the FEM-TMM combination to increase the computational speed of the eigenvalues of flexible structures. ${ }^{35,36}$ It was shown that the error caused by the recursive multiplication of the matrices is minimized, the consumption of memory is reduced, the computational stability is increased, and the repeated eigenvalues are better estimated. When dynamic systems are modelled with rigid bodies, the resulting equations are only approximations of the real vibration and the

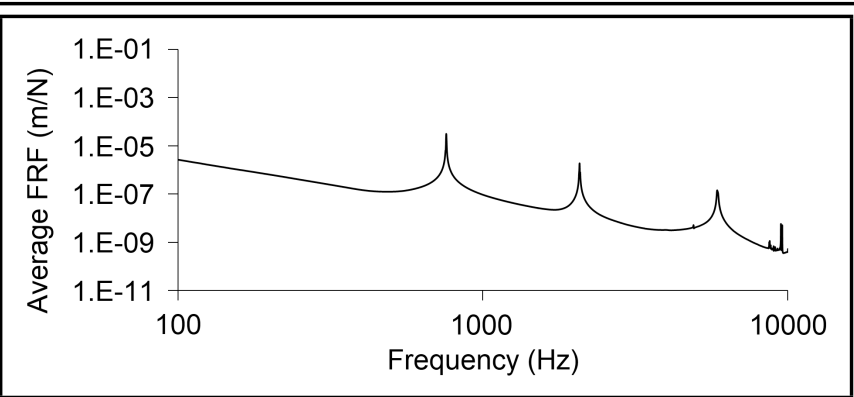

Figure 2. Average frequency response function at rest.

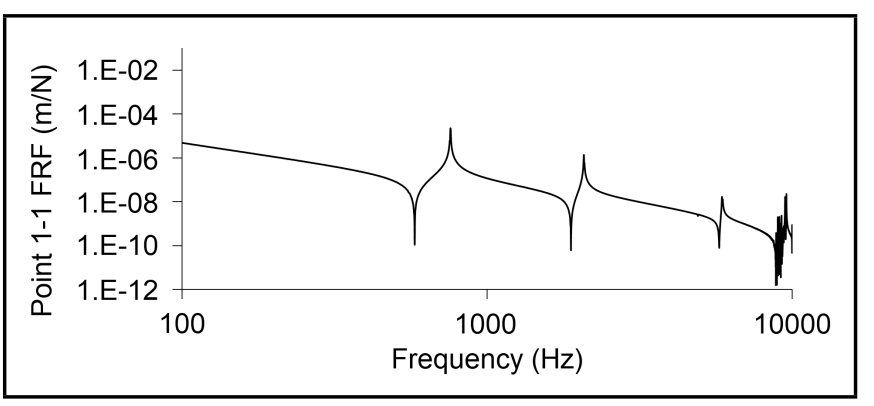

Figure 3. Point 1-1 frequency response function at rest.

approximation quality depends a lot on the degrees of freedom used. ${ }^{37}$ It has been mentioned that vibration modes of a nonrotating rotor can be used to describe the dynamic behaviour of a rotating rotor without losing much accuracy. ${ }^{38-40}$

In our earlier work, we proposed a simple modal approach to get the natural frequencies with a limited number of degrees of freedom (DOFs) but with considerable estimation errors. ${ }^{41}$ Therefore, in this work a theoretical-experimental hybrid method for calculating the natural frequencies and the mode shapes of a turbocharger rotor is proposed. Experimentally it is not easy to get all the bandwidth of a high-speed rotor, however, the mode shapes can be oversampled if the geometry of the rotor allows it. Thus, from an oversampled modal approach based on the axial oversampling, sectioning, and coupling of the rotor, it is possible to use the oversampled mode shapes to increase the degrees of freedom of the system without major complications in the model. This proposal is based on the Nyquist-Shannon theorem and helps to reduce the error in the estimates of natural frequencies and allows to obtain a first approximation of the mode shapes. The natural frequencies were estimated by the TMM and FEM in order to compare the proposed model results with well-founded numerical methods.

\section{MATERIALS AND METHODS}

\subsection{Experimental Method}

A turbocharger rotor of $1.249 \mathrm{~kg}$ was used, Fig. 1, where the turbine is the left wheel and the compressor the right one. The rotor was hanged by two bungees to simulate the free boundary conditions. Thereafter, it was excited with an impact hammer (PCB Piezotronics, Model: 086C03, Sensitivity: $2.25 \mathrm{mV} / \mathrm{N}$ ) to measure the response of the acceleration using a miniature piezoelectric accelerometer (PCB Piezotronics, Model: M353B17, Sensitivity: $10.5 \mathrm{mV} / \mathrm{g}$ ).

When the rotor is excited, the frequency response functions (FRFs) are obtained and processed with an acquisition and pro- 


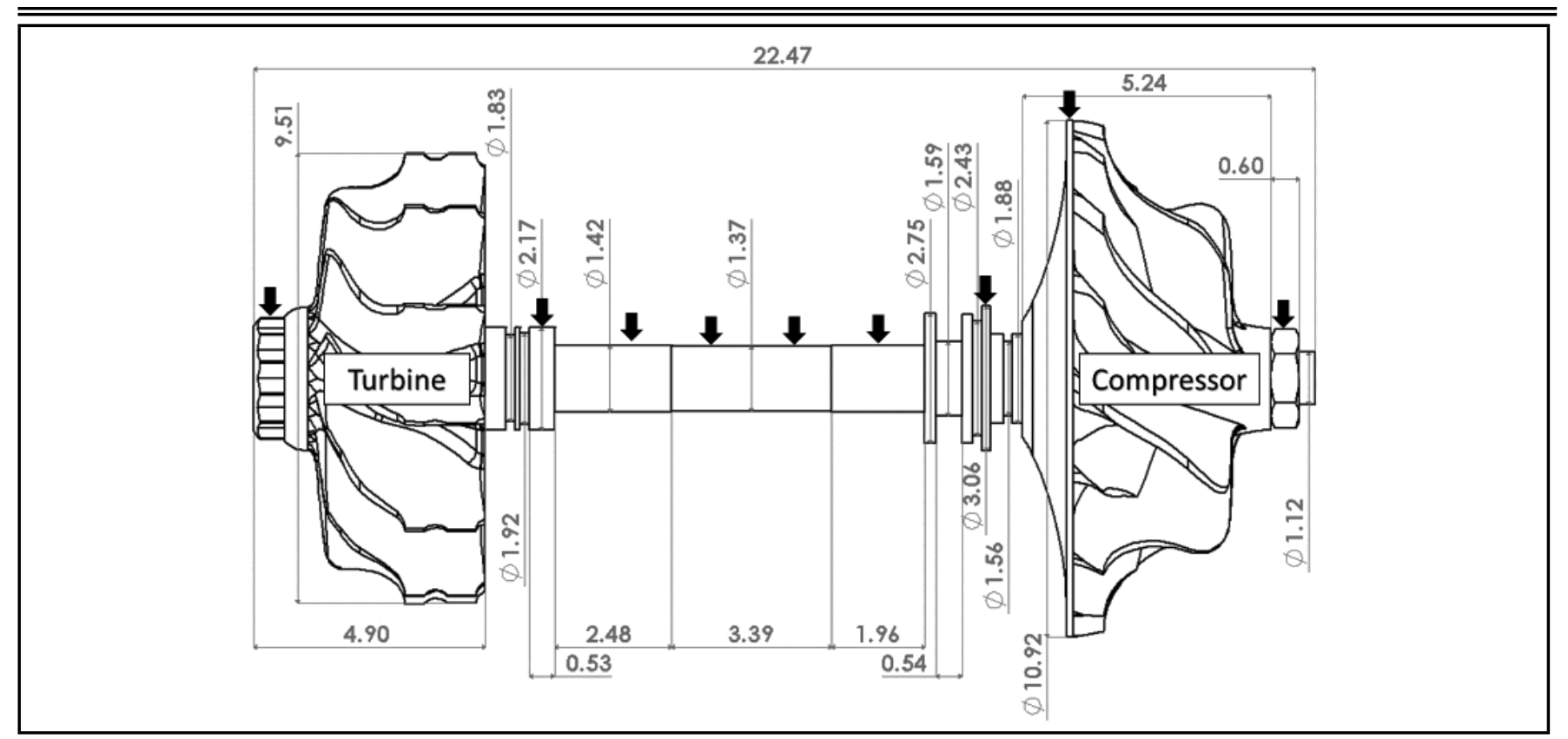

Figure 4. Dimensions (units in $\mathrm{cm}$ ) of the rotor and measurement positions.

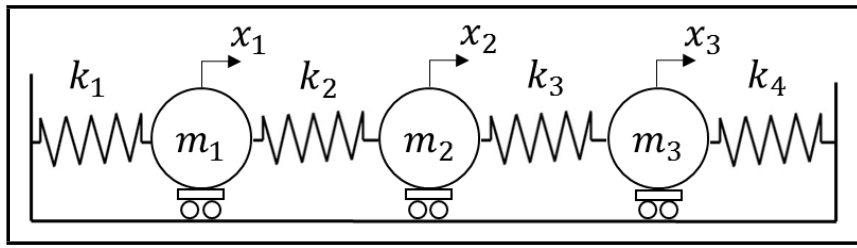

Figure 5. General model proposed.

cessing code using LabVIEW, as well as the calculation of averages. From the recommendations of the API-684 standard for multi-plane balancing of rotors, ${ }^{42}$ only the first three mode shapes obtained experimentally were used in the following modal analysis approach.

The average frequency response function, Fig. 2, was used for the identification of the natural frequencies; instead, the mode shapes were calculated with the imaginary part of the point and transfer FRFs, Fig. 3.

The API-684 standard for multi-planes balancing of rotors recommends analysing the first three critical speeds since their magnitude almost represents the total dissipation energy. Therefore, only the first three natural frequencies were selected, which correspond to the first three resonance peaks, Fig. 2. The natural frequencies are $758.39 \mathrm{~Hz}, 2074.85 \mathrm{~Hz}$, and $5881.14 \mathrm{~Hz}$, and the corresponding bending mode shapes are shown in Fig. 10-12.

Mode shapes represent the discretized solutions of the wave equation in the axial domain, and its axial sampling depends on the dynamic system order that it represents; therefore, the quantities equilibrium of the dynamic eigenvalues (natural frequencies) and the axial eigenvalues are guaranteed.

Nyquist-Shannon theorem states that in order to get a better representation of the waveform when it is discretized, the sampling rate needs to be at least four times the frequency of the highest spectral component. ${ }^{43}$

In this case, considering the API-684 standard, the highest spectral component has an axial period of two thirds of the shaft size; therefore, the Nyquist-Shannon sampling rate recommended is one sixth of the shaft size. Thus, to conserve the quantities equilibrium between the dynamic and axial eigenvalues, it was decided to position the accelerometer in nine points along the rotor with the aim of achieving a greater number of displacements, Fig. 4. This, in order to use a method of axial oversampling of the mode shapes proposed in this paper, is shown in the following section, where the same three natural frequencies, but with a greater number of displacements, it can be achieved a better approximation of the model. The response was measured ten times for each point to reduce the lack of trust where the average FRFs are shown in Fig. 2. The FRFs were taken from the turbine side to the compressor side.

\subsection{Oversampled Modal Approach (OSMA)}

The mathematical morphology of the model proposed here is a set of equations of motion, which comes from the degrees of freedom (DOFs) of the rotor that was obtained from the modal testing. Once the natural frequencies and the oversampled mode shapes are known experimentally, the DOFs for the proposed modal approach are considered the same as the natural frequencies of the frequency spectrum for lateral vibrations. With these DOFs the mode shapes are described enough spatially, but most of the time, at the highest frequencies, the mode shapes have complex forms that cannot be described precisely with few DOFs and more DOFs are needed.

In general, the model proposed uses the modal approach with limited DOFs to model sections of the rotor, which are then coupled to get a larger number of DOFs to describe more accurate natural frequencies and mode shapes. The model takes the experimental displacements and frequencies and computes the coefficients (stiffness and masses) of each modal section; then, the coupling is achieved by adding in parallel the last stiffness of the first section with the first stiffness of the second section and so on with the other sections. The model approach is to explain how the general model is formulated to then explain how the model is oversampled.

The equation of motion for the complete system, Eq. (1), is represented with the following model:

$$
[M]\{\ddot{X}\}+[C]\{\dot{X}\}+[K]\{X\}=\{U(t)\} ;
$$




\begin{tabular}{|c|c|c|c|c|c|c|c|c|c|c|c|}
\hline$[1]$ & & {$\left[k_{1}+k_{2}-\omega_{1}^{2} m\right.$} & $-k_{2}$ & 0 & 0 & 0 & 0 & 0 & 0 & 0 & $\left\lceil X_{1,1}\right]$ \\
\hline 1 & & $-k_{2}$ & $k_{2}+k_{3}-\omega_{1}^{2} m_{2}$ & $k_{2} \quad-k_{3}$ & 0 & 0 & 0 & 0 & 0 & 0 & $X_{1,2}$ \\
\hline 1 & & 0 & $-k_{3} \quad k$ & $k_{3}+k_{4}-\omega_{1}^{2} m_{3}$ & 0 & 0 & 0 & 0 & 0 & 0 & $X_{1,3}$ \\
\hline 1 & $=$ & 0 & 0 & 0 & $-k_{2}$ & $k_{2}+k_{3}-\omega_{2}^{2} m_{2}$ & $-k_{3}$ & 0 & 0 & 0 & $X_{2,2}$ \\
\hline 1 & & 0 & 0 & 0 & 0 & $-k_{3}$ & $k_{3}+k_{4}-\omega_{2}^{2} m$ & 0 & 0 & 0 & $X_{2,3}$ \\
\hline 1 & & 0 & 0 & 0 & 0 & 0 & 0 & $k_{1}+k_{2}-\omega_{3}^{2} m_{1}$ & $-k_{2}$ & 0 & $X_{3,1}$ \\
\hline 1 & & 0 & 0 & 0 & 0 & 0 & 0 & $-k_{2}$ & $k_{2}+k_{3}-\omega_{3}^{2} m_{2}$ & $-k_{3}$ & $X_{3,2}$ \\
\hline [1] & & 0 & 0 & 0 & 0 & 0 & 0 & 0 & $-k_{3}$ & $\left.c_{3}+k_{4}-\omega_{3}^{2} m_{3}\right]$ & {$\left[X_{3,3}\right]$} \\
\hline
\end{tabular}

$$
R=\left[\begin{array}{ccccc}
k_{1,1}+k_{1,2}-\omega^{2} m_{1,1} & -k_{1,2} & 0 & \cdots & 0 \\
-k_{1,2} & k_{1,2}+k_{1,3}-\omega^{2} m_{1,2} & -k_{1,3} & \cdots & 0 \\
0 & -k_{1,3} & k_{1,3}+\left\{k_{1,4}+k_{2,1}\right\}-\omega^{2} m_{1,3} & \ldots & 0 \\
\vdots & \vdots & \vdots & \ddots & -k_{3,3} \\
0 & 0 & 0 & -k_{3,3} & k_{3,3}+k_{3,4}-\omega^{2} m_{3,3}
\end{array}\right] .
$$

where $M, C$, and $K$ are the mass, damping, and stiffness matrix, respectively. As the particular interest of this research is the free and undamped vibration, so Eq. (2) is given by

$$
[M]\{\ddot{X}\}+[K]\{X\}=0 .
$$

The turbocharger rotor showed several experimental natural frequencies, which means that several degrees of freedom are required. In this case, only the first three will be considered because it is a high-speed rotor and therefore has a difficulty to obtain high frequencies values experimentally. The general model proposed in Fig. 5 is the kind of spring-mass model used by $\mathrm{M}$. Yu et al., ${ }^{44}$ to get the modal parameters. The model in Fig. 5 is based on the first three estimated natural frequencies and mode shapes, which have higher amplitudes, so the system equations can be represented in Eq. (3) as follows:

$$
\begin{aligned}
& u_{1}(t)=m_{1} \ddot{x}_{1}+k_{2}\left(x_{1}-x_{2}\right)+k_{1} x_{1} ; \\
& u_{2}(t)=m_{2} \ddot{x}_{2}+k_{2}\left(x_{2}-x_{1}\right)+k_{3}\left(x_{2}-x_{3}\right) ; \\
& u_{3}(t)=m_{3} \ddot{x}_{3}+k_{3}\left(x_{3}-x_{2}\right)+k_{4} x_{3} .
\end{aligned}
$$

Then, expressing the model in Eq. (3) in the frequency domain and ordering in matrix form

$$
\begin{aligned}
& {\left[\begin{array}{l}
F_{1}(\omega) \\
F_{2}(\omega) \\
F_{3}(\omega)
\end{array}\right]=} \\
& {\left[\begin{array}{ccc}
k_{1}+k_{2}-\omega^{2} m_{1} & -k_{2} & 0 \\
-k_{2} & k_{2}+k_{3}-\omega^{2} m_{2} & -k_{3} \\
0 & -k_{3} & k_{3}+k_{4}-\omega^{2} m_{3}
\end{array}\right]\left[\begin{array}{l}
X_{1}(\omega) \\
X_{2}(\omega) \\
X_{3}(\omega)
\end{array}\right] \text {, }}
\end{aligned}
$$

or

$$
[U]_{3 \times 1}=[A]_{3 \times 3}[X]_{3 \times 1} ;
$$

where the matrix $U$ is the force vector, while $X$ is the displacement vector and $A$ is the system matrix.
Experimentally, impact forces $(U(\omega)=1)$ excite the mode shapes (axial eigenvalues $X_{n}$ ) of the rotor, at its corresponding frequency (dynamic eigenvalues $\omega_{n}$ ). Thus, the system can be expressed in terms of its three first modes as follows in Eq. (5), this system solution can be restarted as given in Eq. (6), or

$$
[U]_{9 \times 1}=[D]_{9 \times 7}[M K]_{7 \times 1} .
$$

Then, in order to calculate the dynamic parameters at the $[M K]_{7 \times 1}$ matrix, the pseudo-inverse of the $[D]_{9 \times 7}$ matrix is used

$$
[M K]_{7 \times 1}=[D]_{7 \times 9}^{-1}[U]_{9 \times 1} .
$$

The methodology shown above is considering the general proposed model for the complete rotor. However, the OSMA consists, in general, to cut the rotor in sections which have the same number of nodal points in order to conserve the quantities equilibrium of the dynamic and axial eigenvalues for each section, then the proposed general model is applied for each uncoupled section, as in Fig. 6, using the corresponding frequencies and displacements of the first, second, and third mode shape of each section, as well as the respective mass of the section, data which are known. For example, for the first section the displacements values of the proposed general model $x_{1}, x_{2}$, and $x_{3}$, now would be $x_{1,1}, x_{1,2}$, and $x_{1,3}$, to obtain a matrix $M K$ for the first section as in Fig. 6 .

The resulted masses from the matrix $M K$ are normalized with the total mass of each rotor section to ensure the mass magnitude of the complete rotor in the final vector. The analysis has to be repeated for the following sections of the rotor to calculate the stiffnesses and masses corresponding to each section; in other words, to obtain the remaining $M K$ matrices.

After obtaining all values of stiffness and mass of the sections, the resulting matrix $R$, which follows the model in Eq. (5), is constructed by making the coupling of the sections adding in parallel the last stiffness of the first section with the 


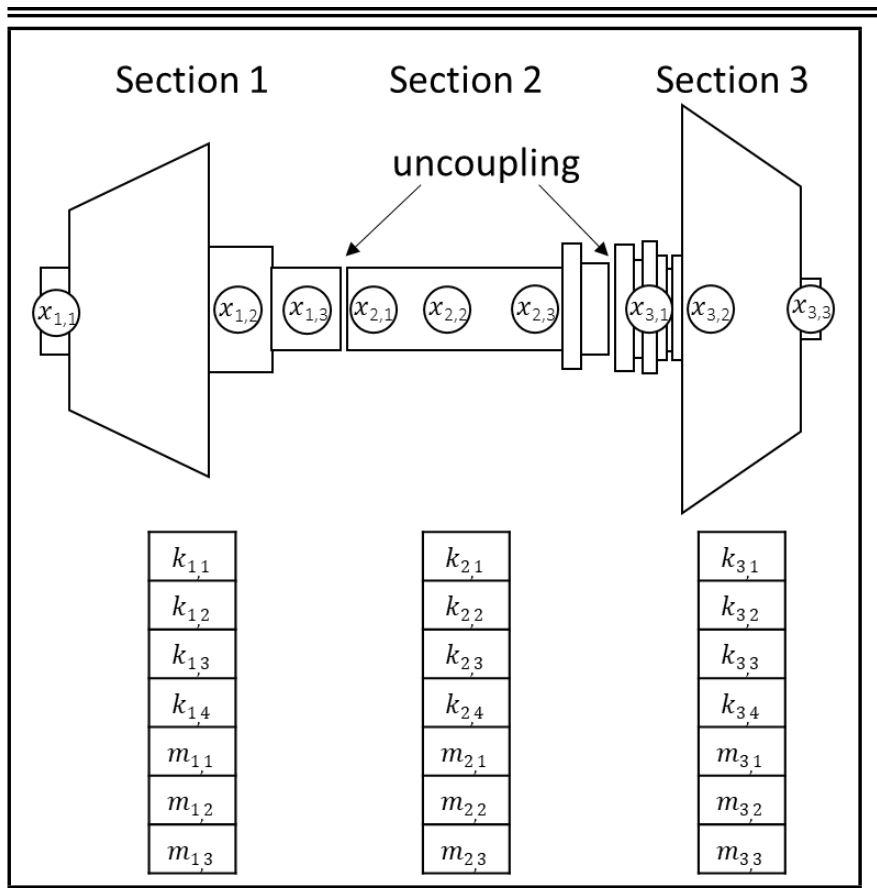

Figure 6. Rotor sectioning.

first stiffness of the adjacent section, as shown in Eq. (9), and so on with the following sections until getting a total of ten coupled stiffnesses for this case of study. Therefore, the eigenvalues and eigenvectors are calculated from Eq. (9) and consequently the estimated natural frequencies and mode shapes.

\subsection{Transfer Matrix Method}

Figure 7 shows a 24-inertia model of the turbocharger rotor. It was decided to divide the shaft segments into inertias to obtain a better estimation of the high frequencies. The algorithm was programmed in MATLAB and was designed only to obtain the natural frequencies. The stiffness and inertias correspond to the bending stiffness and the mass moment of inertia, respectively. A Young modulus of $200 \mathrm{GPa}$ and a density of $7850 \mathrm{~kg} / \mathrm{m}^{3}$ was used for the turbine, shaft, bushings, and nut, while $71 \mathrm{GPa}$ and $2770 \mathrm{~kg} / \mathrm{m}^{3}$ was used for the compressor. The bushings and the shaft were considered as one solid part.

\subsection{Finite Element Method}

The rotor was modelled using ANSYS, which is a finite element software. It was used 20 nodes, 90 one-dimensional elements type BEAM188. The turbine, the compressor, and the pressure nut were modelled as real constants using the element type MASS21, which concentrates the masses and inertias of the mentioned components. The Young modulus and density of the materials used for this analysis were the same as the model with the transfer matrix method. The block lanczos method was used for modal extraction and the modes were normalized with the mass matrix. Figure 8 shows the discretization of the rotor. Figure 9 shows the mode shapes estimated with this method.

\section{RESULTS AND DISCUSION}

The results of the estimated natural frequencies by the different methods used in this work are shown in Table 1, as well as the percentage of relative errors with respect to the experimental measures. Figures 10-12 show the mode shapes estimated by the OSMA compared with the modal testing results. The errors in the natural frequencies with OSMA are in the order of other commonly used methods, with an RMS of $8.85 \%$. Although the error of the second mode is higher, there are works that show the magnitude of this error is within the order in the literature. M. Yu et al. obtained the natural frequencies of the foundation of a rotor system using the diagonal mass matrix approach and the general matrix approach ${ }^{44}$ with an error in the first flexible mode of $20 \%$ and $2.2 \%$ using the first and second methods respectively, compared with ANSYS results. R. K. Behera et al. estimated the natural frequencies of a cantilever beam using FEM, ${ }^{45}$ showing errors of up to $4 \%$ in the first three natural frequencies in relation to experimental results. A. Entezari et al. calculated the natural frequencies of a rotor with 3 disks with different diameter, thickness, and a uniform shaft, ${ }^{46}$ in which errors of up to $12.36 \%$ are shown, using various models in 1D FE with Carrera Unified Formulation in relation with 3D FE in ANSYS. F. Bakhtiari-Nejad et al. used an analytical estimate based on the Rayleigh's method to calculate the natural frequencies and mode shapes of a beam with different cracks configurations. ${ }^{47}$ Relative errors of up to $66 \%$ with respect to an exact numerical method were shown, considering the first three natural frequencies and the deepest cracks. H. J. Kang et al. proposed a dynamic model for free vibration of arch bridges based on the TMM, to calculate the natural frequencies and mode shapes. ${ }^{48}$ Errors of up to $4.2 \%$ are shown with respect to the FEM by analysing the first seven natural frequencies and different boundary conditions. R. Tamrakar and N. D. Mittal showed that the shear effect and rotary inertia improve the prediction of the dynamic performance of a rotor system. ${ }^{49}$ It was shown when using different theories (Euler-Bernoulli, Rayleigh, and Timoshenko) to model the beam element, errors of up to $10.23 \%$ in the natural frequencies are observed in relation to experimental measurements. G. Mogenier et al. calculated the modal parameters of a rotor using a FE branched model. ${ }^{50}$ The predicted lateral natural frequencies showed an error of up to $6.5 \%$ compared with measurements. M. H. Jalali et al. determined the natural frequencies of a rotor using a 1D-beam model. ${ }^{51}$ The natural frequencies showed errors of up to $22 \%$ in relation with $3 \mathrm{D}$ FEM and up to $13 \%$ with experimental results. M. Boiangiu et al. used the TMM for a vibration analysis of a conic beam in cantilever. ${ }^{52}$ Considering cylindrical elements, the percentage error in the first five natural frequencies varied between $2.2 \%$ to $7.3 \%$ compared with measurements. A. Bencomo Angeles et al. calculated the natural frequencies of an experimental flexible rotor with a modified TMM ${ }^{53}$ An error of up to $6.62 \%$ in relation with experimental modal analysis and up to $12.41 \%$ compared to run-down measures was reported. D. Violante et al. calculated the natural frequencies and mode shapes of flexible rotors with the TMM. ${ }^{54}$ An error of up to $14.4 \%$ in natural frequencies compared with an experimental test rig and up to $4.9 \%$ with a real gas turbine rotor was reported. H. Y. Lin proposed a numerical assembly method (NAM) to investigate the free vibration of a Timoshenko beam with multiple point masses and different kind of springs. ${ }^{55}$ Errors of up to $82 \%$ in the natural frequencies with respect to the Euler-Bernoulli beam and different configurations of point masses, inertias and springs, were shown. In a more recent work by M. Yu et al., ${ }^{56}$ 
Turbine side

Compressor side

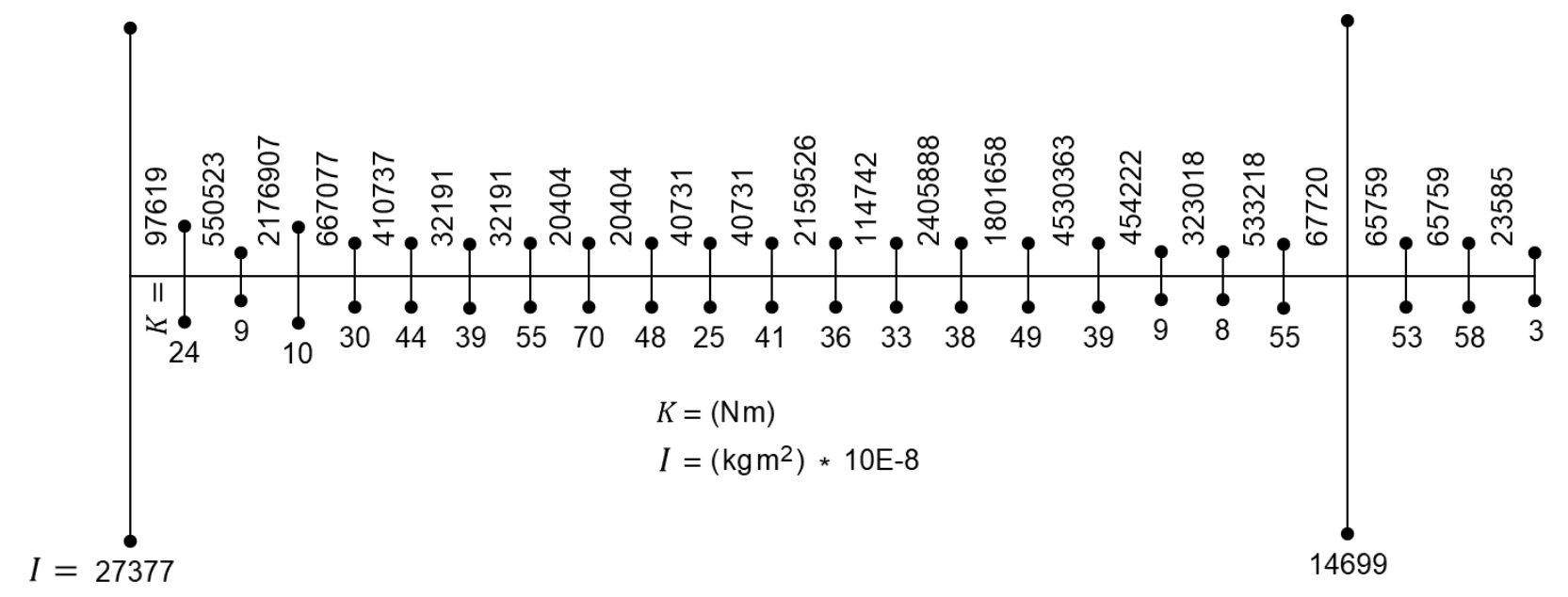

Figure 7. 24-inertia model of the turbocharger rotor.

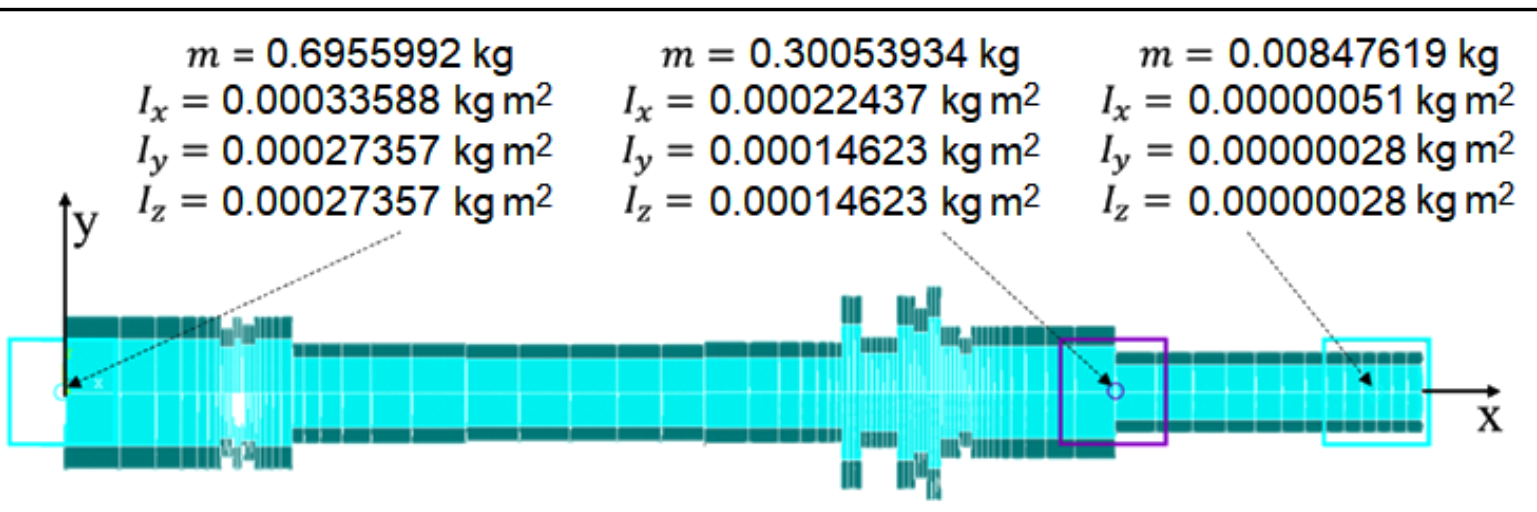

Figure 8. Discretization of the rotor.

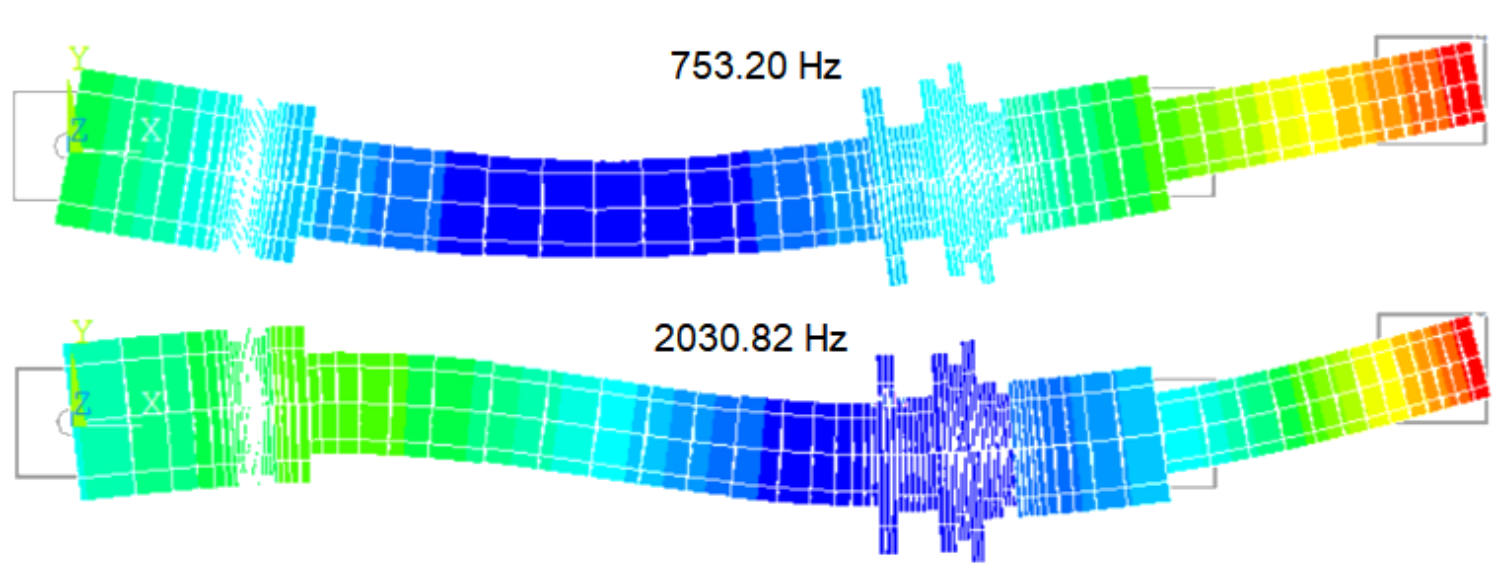

$5321.80 \mathrm{~Hz}$

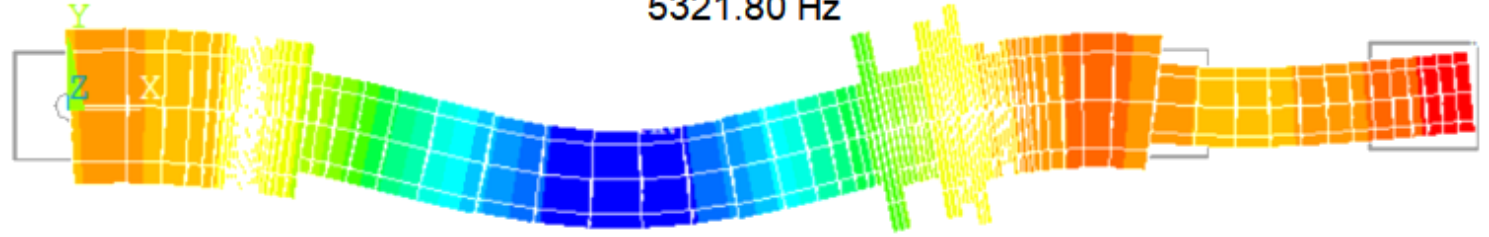

Figure 9. Mode shapes estimated with FEM. 
Table 1. Natural frequencies $(\mathrm{Hz})$ and percentage relative errors compared with the modal testing results.

\begin{tabular}{|c|c|c|c|c|c|c|c|}
\hline Mode & $\begin{array}{c}\text { Modal } \\
\text { testing }\end{array}$ & TMM & 1D-FEM & OSMA & $\begin{array}{c}\% \\
\text { TMM }\end{array}$ & $\begin{array}{c}\% \\
\text { 1D-FEM }\end{array}$ & $\begin{array}{c}\% \\
\text { OSMA }\end{array}$ \\
\hline 1 & 758.39 & 757.43 & 753.20 & 789.433 & -0.13 & -0.68 & 4.09 \\
2 & 2074.85 & 2114.52 & 2030.82 & 1779.44 & 1.91 & -2.12 & -14.24 \\
3 & 5881.14 & 5500.72 & 5321.80 & 6115.48 & -6.47 & -9.51 & 3.98 \\
\hline
\end{tabular}

errors from $0.47-10.88 \%$ are shown in the first five natural frequencies for the foundation of a rotor system, estimated with impact tests compared with FEM results.

The non-contact measurement instruments, such as lasertype instruments, will become more viable due the high precision, non-intrusiveness, and fast measurement. ${ }^{3}$ Therefore, the model in our work would have no problem since the displacements of the mode shapes, which are used as input data, would be more easily detected.

It has been shown that the estimation of finding determinants equal to zero can be improved using recursive algorithms, ${ }^{37}$ so it could be a viable way to reduce the error in estimating natural frequencies by modifying the stiffness values in the resulting dynamic stiffness matrix for each section of the proposed model. The contact effects on the stiffness of the system, as well as correction coefficients, can be used to improve the estimation of eigenvalues, as has been shown in other studies. ${ }^{32,57}$

The trend of the estimated mode shapes is approximated; however, it does not exceed the estimated mode shapes with FEM. The Modal Assurance Criterion (MAC) for evaluating the similarity of two mode shapes was used between the OSMA estimated mode shapes and the experimental modes, Figs. 13-15. The MAC values for the estimated-experimental modes are $43.16 \%, 36.02 \%$, and $18.74 \%$ for the first, second, and third mode shapes, respectively.

The mode shapes estimated in this paper maintain the tendency of the mode shapes estimated with FEM in the work of H. Taplak and M. Parlak, ${ }^{16}$ where only the first four modes are analysed but under supported conditions. The modes also resemble those estimated in the work of M. H. Jalali et al., ${ }^{51}$ which were obtained at rest by the beam model. The nine measurement points considered in the experimental mode shapes of this paper coincide with the number of points in the work of Y. Li et al., ${ }^{58}$ in which it was obtained with an error of up to $10.88 \%$ in the estimation of natural frequencies, but good approximation of mode shapes. These works mentioned to contrast the mode shapes, use rotors similar to the one used in this paper.

\section{CONCLUSIONS}

In the OSMA, the experimental mode shapes of a high-speed rotor are oversampled to get a better spatial approximation, and theoretically, the rotor is sectioned and then coupled to model the complete system using a reduced number of DOFs. This oversampling criterion can be used to reduce the error in the estimates of the natural frequencies and to have a first approximation of the mode shapes. The rough model was presented here; however, recursive algorithms and correction coefficients using the damping of the system, could help to approximate the mode shapes and reduce even more the error in the natural frequencies.

The model does not require deep knowledge of the geometry and does not consume many computational resources.

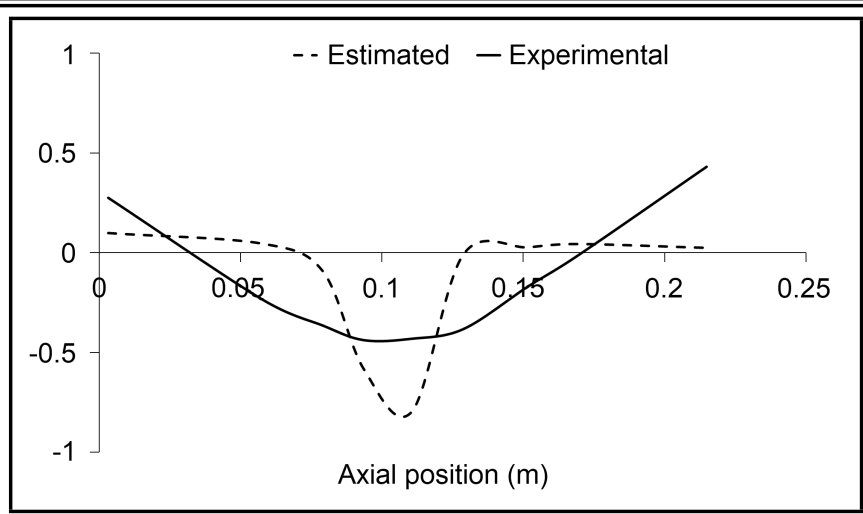

Figure 10. First mode shape.

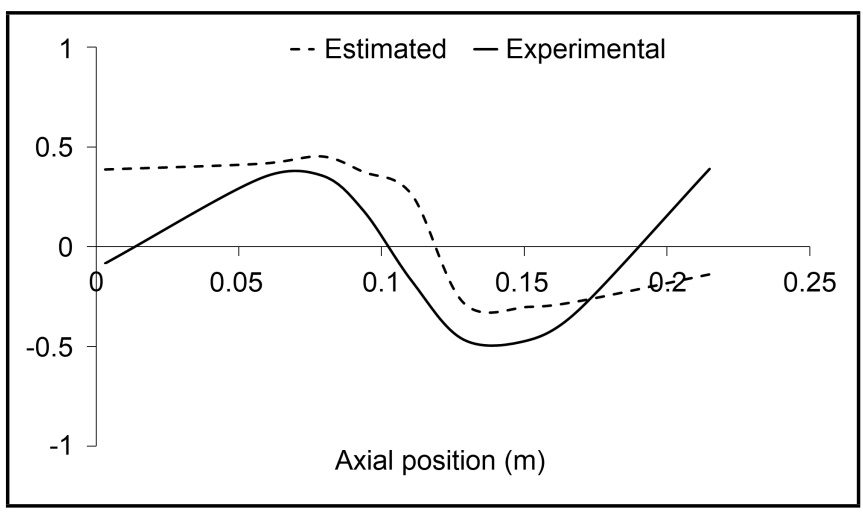

Figure 11. Second mode shape.

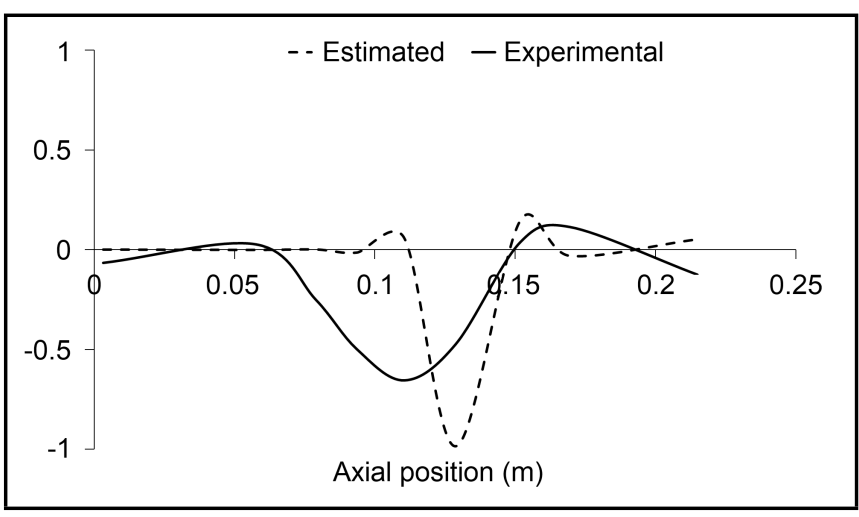

Figure 12. Third mode shape.

Work continues in that each section separately approximates the natural frequencies and its respective section of mode shape in order to reduce even more errors in the frequencies and to estimate better complete mode shapes.

\section{ACKNOWLEDGEMENTS}

The author thanks CONACYT for the support through its program of doctoral scholarship (492895), as well as thanks to the LaNITeF.

\section{REFERENCES}

1 Behzad, M., Alvandi, M., Mba, D., and Jamali, J. A finite element-based algorithm for rubbing induced vibration prediction in rotors, Journal of Sound and Vibration, 332 (21), 5523-5542, (2013). https://dx.doi.org/10.1016/j.jsv.2013.05.016 


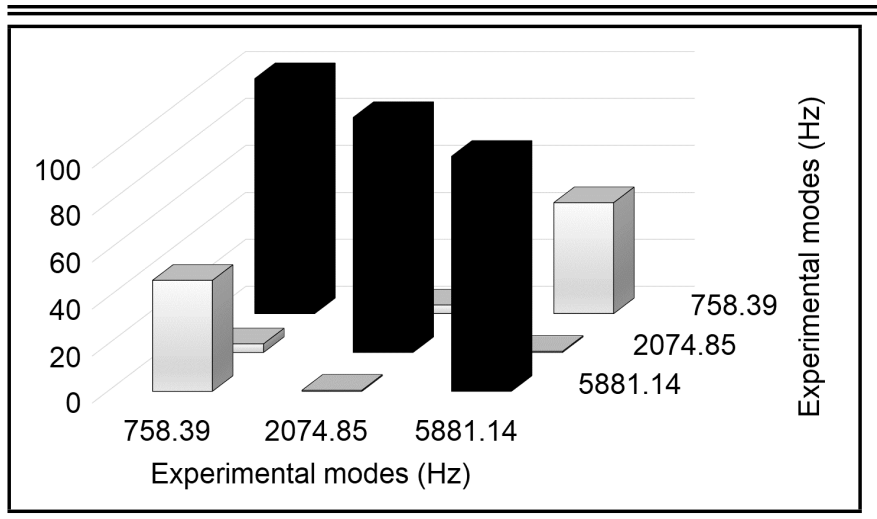

Figure 13. MAC matrix for the experimental-experimental modes.

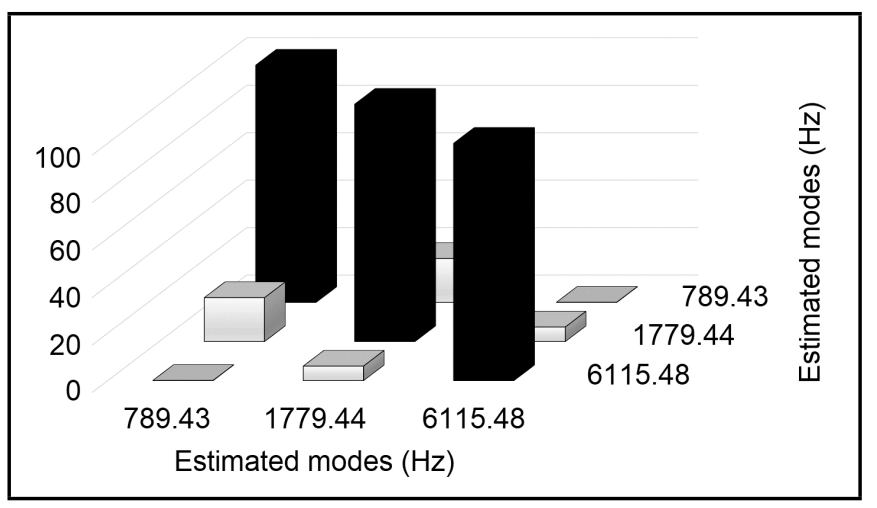

Figure 14. MAC matrix for the estimated-estimated modes.

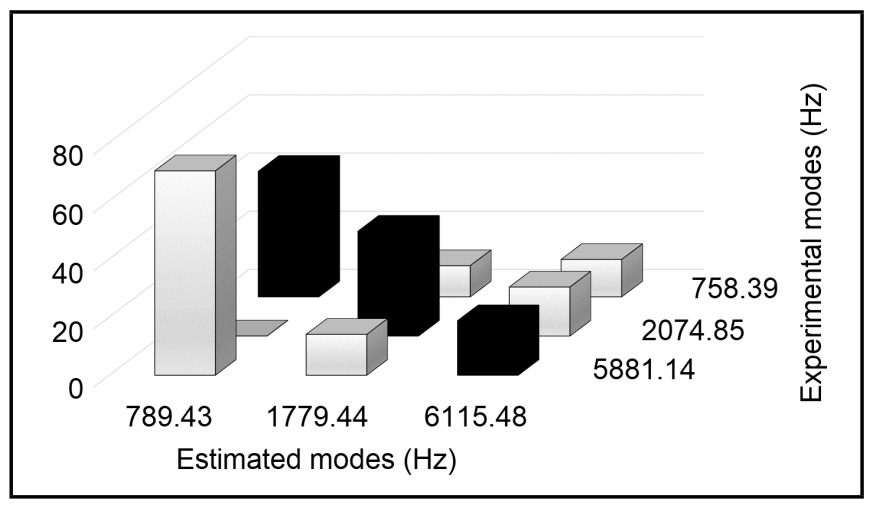

Figure 15. MAC matrix for the estimated-experimental modes.

2 Liu, L., Cao, D., and Sun, S. Dynamic characteristics of a disk-drum-shaft rotor system with rubimpact, Nonlinear Dynamics, 80 (1-2), 1017-1038, (2015). https://dx.doi.org/10.1007/s11071-015-1925-4

3 Goyal, D. and Pabla, B. S. The vibration monitoring methods and signal processing techniques for structural health monitoring: a review, Archives of Computational Methods in Engineering, 23 (4), 585-594, (2016). https://dx.doi.org/10.1007/s11831-015-9145-0

4 Wiedermann, A., Frank, D., Orth, U., and Beukenberg, M. Computational and experimental analysis of an industrial gas turbine compressor, Proceedings of the ASME 2011 Turbo Expo: Turbine Technical Conference and Exposition. Volume 7: Turbomachinery, 319-329, (2011). https://dx.doi.org/10.1115/GT2011-46336

5 Poursaeidi, E., Babaei, A., Mohammadi Arhani,
M. R., and Arablu, M. Effects of natural frequencies on the failure of R1 compressor blades, Engineering Failure Analysis, 25, 304-315, (2012). https://dx.doi.org/10.1016/j.engfailanal.2012.05.013

6 Moore, J., Vannini, G., Camatti, M., and Bianchi, P. Rotordynamic analysis of a large industrial turbocompressor including finite element substructure modeling, Journal of Engineering for Gas Turbines and Power, 132 (8), 082401082401-9, (2010). https://dx.doi.org/10.1115/1.2938272

7 Saxena, A., Chouksey, M., and Parey, A. Effect of mesh stiffness of healthy and cracked gear tooth on modal and frequency response characteristics of geared rotor system, Mechanism and Machine Theory, 107, 261-273, (2017). https://dx.doi.org/10.1016/j.mechmachtheory.2016.10.006

8 Ewins, D. J. Modal Testing: Theory, Practice and Application, Research Studies Press, Baldock, Hertfordshire, England, (2000).

9 Majewski Szymiec, T. Vibraciones en Sistemas Físicos, Alfaomega grupo editor, Mexico, (2016).

$10 \mathrm{He}$, J. and Fu, Z-F. Modal Analysis, ButterworthHeinemann, (2001).

11 Choi, S.-T. and Mau, S.-Y. Dynamic analysis of geared rotor-bearing systems by the transfer matrix method, Journal of Mechanical Design, 123 (4), 562-568, (1999). https://dx.doi.org/10.1115/1.1415739

12 Zhang, Y. and Du, Z. Dynamic characteristics calculation study of a gas turbine rod fastening rotor, Proceedings of the 2009 Asia-Pacific Power and Engineering Conference, 1-4, Wuhan, China, (2009). https://dx.doi.org/10.1109/APPEEC.2009.4918298

13 Xu, G., Zhou, J., Geng, H., Lu, M., and Cheng, W. Unbalance response analysis of the circumferential tie-rod combined rotor considering different support, Proceedings of the 2014 IEEE International Conference on Mechatronics and Automation, 1323-1328, Tianjin, China, (2014). https://dx.doi.org/10.1109/ICMA.2014.6885891

14 Lu, M., Geng, H., Yang, B., and Yu, L. Finite element method for disc-rotor dynamic characteristics analysis of gas turbine rotor considering contact effects and rod preload, Proceedings of the 2010 IEEE International Conference on Mechatronics and Automation, 1179-1183, Xi'an, China, (2010). https://dx.doi.org/10.1109/ICMA.2010.5587948

15 Liu, X., Yuan, Q., Liu, Y., and Gao, J. Analysis of the stiffness of hirth couplings in rod-fastened rotors based on experimental modal parameter identification, Proceedings of the ASME Turbo Expo 2014: Turbine Technical Conference and Exposition. Volume 7A: Structures and Dynamics, V07AT31A027, (2014). https://dx.doi.org/10.1115/GT2014-26448

16 Taplak, H. and Parlak, M. Evaluation of gas turbine rotor dynamic analysis using the finite element method, Measurement, 45 (5), 1089-1097, (2012). https://dx.doi.org/10.1016/j.measurement.2012.01.032 
17 Pagar, N. D. and Gawande, S. H. Investigations of dynamic characteristics of eccentric rotary shaft of wankelengine, Journal of Mechanical Design and Vibration, 2 (2), 53-59, (2014). https://dx.doi.org/10.12691/jmdv-2-2-3

18 Fegade, R., Patel, V., Nehete, R. S., and Bhandarkar, B. M. Unbalanced response of rotor using ANSYS parametric design for different bearings, International Journal of Engineering Sciences \& Emerging Technologies, 7 (1), 506515, (2014).

19 Ramírez Vargas, I., Palacios Pineda, L. M. and Corro Hernández, H. Respuesta vibratoria de un rotor apoyado en chumaceras hidrodinámicas cortas, Memorias del XIX Congreso Internacional Anual de la SOMIM, 1085-1093, Hidalgo, Mexico, (2013).

20 Lee, A., Shih, Y., and Kang, Y. The analysis of linear rotorbearing systems: a general transfer matrix method, Journal of Vibration and Acoustics, 115 (4), 490-497, (1993). https://dx.doi.org/10.1115/1.2930377

21 Kang, Y., Lee, A., and Shih, Y. A modified transfer matrix method for asymmetric rotor-bearing systems, Journal of Vibration and Acoustics, 116 (3), 309-317, (1994). https://dx.doi.org/10.1115/1.2930430

${ }^{22} \mathrm{Zu}, \mathrm{J}$. W. and Ji, Z. An improved transfer matrix method for steady-state analysis of nonlinear rotorbearing systems, Journal of Engineering for Gas Turbines and Power, 124 (2), 303-310, (2002). https://dx.doi.org/10.1115/1.1447235

23 Chai, S., Gang, X., and Qu, Q. A whole transfer matrix method for the eigensolutions of multirotor systems, Proceedings of the ASME 2005 Power Conference, 457-463, Chicago, Illinois, USA, (2005). https://dx.doi.org/10.1115/PWR2005-50159

24 Varney, P. and Green, I. Rotordynamic analysis using the complex transfer matrix, Proceedings of the ASME 2012 International Design Engineering Technical Conferences and Computers and Information in Engineering Conference. Volume 6: 1st Biennial International Conference on Dynamics for Design; 14th International Conference on Advanced Vehicle Technologies, 237-246, (2012). https://dx.doi.org/10.1115/DETC2012-70643

25 Lee, J. W. and Lee, J. Y. A transfer matrix method capable of determining the exact solutions of a twisted Bernoulli-Euler beam with multiple edge cracks, Applied Mathematical Modelling, 41, 474-493, (2016). https://dx.doi.org/10.1016/j.apm.2016.09.013

26 Lee, J. W. and Lee, J. Y. An exact transfer matrix expression for bending vibration analysis of a rotating tapered beam, Applied Mathematical Modelling, 53, 167188, (2018). https://dx.doi.org/10.1016/j.apm.2017.08.022

27 Rong, B., Rui, X., Lu, K., Tao, L., Wang, G., and $\mathrm{Ni}$, X. Transfer matrix method for dynamics modeling and independent modal space vibration control design of linear hybrid multibody system, Mechanical Systems and Signal Processing, 104, 589-606, (2018). https://dx.doi.org/10.1016/j.ymssp.2017.10.030
$28 \mathrm{Wu}$, J. and Chen, C. A lumped-mass TMM for free vibration analysis of a multi-step Timoshenko beam carrying eccentric lumped masses with rotary inertias, Journal of Sound and Vibration, 301 (3-5), 878-897, (2007). https://dx.doi.org/0.1016/j.jsv.2006.10.022

29 Al-Bahkali, E. and ElMadany, M. Dynamic analysis of rotating machinery using computer aided design approach, Proceedings of STCEX, 3, 192-201, Riyadh, Saudi Arabia, (2004).

$30 \mathrm{Zu}, \mathrm{J} . \mathrm{W}$. and Ji, Z. An improved transfer matrix method for steady-state analysis of nonlinear rotorbearing systems, Journal of Engineering for Gas Turbines and Power, 124 (2), 303-310, (2002). https://dx.doi.org/10.1115/1.1447235

31 Ghasemalizadeh, O., Reza Mirzaee, M., Hossein, S., and Ahmadian, M. T. Rotor bearing system analysis using the transfer matrix method with thickness assumption of disk and bearing, International Journal of Mechanical, Industrial and Aerospace Engineering, 2 (4), 206-213, (2008).

32 Meng, C., Su, M., and Wang, S. An investigation on dynamic characteristics of a gas turbine rotor using an improved transfer matrix method, Journal of Engineering for Gas Turbines and Power, 135 (12), 122505-122505-8, (2013). https://dx.doi.org/10.1115/1.4025234

33 Lee, J. W. and Lee J. Y. Free vibration analysis using the transfer-matrix method on a tapered beam, Computers and Structures, 164, 75-82, (2016). https://dx.doi.org/10.1016/j.compstruc.2015.11.007

34 Lee, J. W. and Lee, J. Y. A transfer matrix method capable of determining the exact solutions of a twisted Bernoulli-Euler beam with multiple edge cracks, Applied Mathematical Modelling, 41, 474-493, (2017). https://dx.doi.org/10.1016/j.apm.2016.09.013

35 Rong, B., Rui, X., and Wang, G. Modified finite element transfer matrix method for eigenvalue problem of flexible structures, Journal of Applied Mechanics, 78 (2), 021016021016-7, (2010). https://dx.doi.org/10.1115/1.4002578

36 Rong, B., Rui, X., and Tao, L. Perturbation finite element transfer matrix method for random eigenvalue problems of uncertain structures, Journal of Applied Mechanics, 79 (2), 021005-021005-8, (2012). https://dx.doi.org/10.1115/1.4005574

37 Bestle, D., Abbas, L., and Rui, X. Recursive eigenvalue search algorithm for transfer matrix method of linear flexible multibody systems, Multibody System Dynamics, 32 (4), 429-444, (2014). https://dx.doi.org/10.1007/s11044013-9399-y

38 Jacquet-Richardet, G., Ferraris, G., and Rieutord, P. Frequencies and modes of rotating flexible bladed disc-shaft assemblies: a global cyclic symmetry approach, Journal of Sound and Vibration, 191 (5), 901-915, (1996). https://dx.doi.org/10.1006/jsvi.1996.0162 
${ }^{39}$ Chatelet, E., D'Ambrosio, F., and Jacquet-Richardet, G. Toward global modelling approaches for dynamic analyses of rotating assemblies of turbomachines, Journal of Sound and Vibration, 282 (1-2), 163-178, (2005). https://dx.doi.org/10.1016/j.jsv.2004.02.035

${ }^{40}$ Meng, M. W., Jun, W. J., and Zhi, W. Frequency and stability analysis method of asymmetric anisotropic rotorbearing system based on three-dimensional solid finite element method, Journal of Engineering for Gas Turbines and Power, 137 (10), 102502-102502-9, (2015). https://dx.doi.org/10.1115/1.4029968

${ }^{41}$ Montoya, L. A., Rodríguez, E. E., Zúñiga, H. J., and Mejía, I. Dynamic model for high-speed rotors based on their experimental characterization, Application and Theory of Computer Technology, 2 (4), 25-34, (2017). https://dx.doi.org/10.22496/atct.v2i4.108

42 API 684, API Standard Paragraphs Rotordynamic Tutorial: Lateral Critical Speeds, Unbalance Response, Stability, Train Torsionals, and Rotor Balancing (2nd Edition), Washington D.C., API Publishing Services, (2005).

${ }^{43}$ Jerri, A. J. The Shannon sampling theorem-Its various extensions and applications: A tutorial review, Proceedings of the IEEE, 65 (11), 1565-1596, (1977). https://dx.doi.org/10.1109/PROC.1977.10771

${ }^{44}$ Yu, M., Feng, N., and Hahn, E. J. On the identification of the modal parameters for a flexible turbomachinery foundation, Proceedings of the ASME Turbo Expo 2012: Turbine Technical Conference and Exposition. Volume 7: Structures and Dynamics, 1075-1083, (2012). https://dx.doi.org/10.1115/GT2012-68291

45 Behera, R. K., Pandey, A., and Parhi, D. R. Numerical and experimental verification of a method for prognosis of inclined edge crack in cantilever beam based on synthesis of mode shapes, Procedia Technology, 14, 67-74, (2014). https://dx.doi.org/10.1016/j.protcy.2014.08.010

${ }^{46}$ Entezari, A., Filippi, M., and Carrera, E. On dynamic analysis of variable thickness disks and complex rotors subjected to thermal and mechanical prestresses, Journal of Sound and Vibration, 405, 68-85, (2017). https://dx.doi.org/10.1016/j.jsv.2017.05.039

47 Bakhtiari-Nejad, F., Khorram, A., and Rezaeian, M. Analytical estimation of natural frequencies and mode shapes of a beam having two cracks, International Journal of Mechanical Sciences, 78, 193-202, (2014). https://dx.doi.org/10.1016/j.ijmecsci.2013.10.007

48 Kang, H. J., Xie, W. D., and Guo, T. D. Modeling and parametric analysis of arch bridge with transfer matrix method, Applied Mathematical Modelling, 40 (23-24), 10578-10595, (2016). https://dx.doi.org/10.1016/j.apm.2016.07.009

49 Tamrakar, R. and Mittal, N. D. Modal behaviour of rotor considering rotary inertia and shear effects, Perspectives in Science, 8, 87-89, (2016). https://dx.doi.org/10.1016/j.pisc.2016.04.003
${ }^{50}$ Mogenier, G., Baranger, T. N., Dufour, R., Durantay, L., and Baras, N. Efficient model development for an assembled rotor of an induction motor using a condensed modal functional, Journal of Computational and Nonlinear Dynamics, 6 (2), 021011-021011-8, (2011). https://dx.doi.org/10.1115/1.4002381

51 Jalali, M. H., Ghayour, M., Ziaei-Rad, S., and Shahriari, B. Dynamic analysis of a high speed rotorbearing system, Measurement, 53, 1-9, (2014). https://dx.doi.org/10.1016/j.measurement.2014.03.010

52 Boiangiu, M., Ceausu, V., and Untaroiu, C. D. A transfer matrix method for free vibration analysis of EulerBernoulli beams with variable cross section, Journal of Vibration and Control, 22 (11), 2591-2602, (2014). https://dx.doi.org/10.1177/1077546314550699

53 Bencomo Angeles, A., Hernández Marceliz, E., García Reynoso, A. C., and de Guevara Durán, E. L. Determinación de las características dinámicas de un rotor flexible experimental usando el método de Holzer, Memorias del XVI Congreso Internacional Anual de la SOMIM, 1-9, Mexico, (2010).

54 Violante, D., Palmieri, F., and Klempnow, A. Aplicación del método de la matriz de transferencia para la determinación de las formas modales y velocidades críticas en rotores flexibles, III Congreso Argentino de Ingeniería Mecánica, 1-12, Argentina, (2012).

55 Lin, H. Y. On the natural frequencies and mode shapes of a multispan Timoshenko beam carrying a number of various concentrated elements, Journal of Sound and Vibration, 319 (1-2), 593-605, (2009). https://dx.doi.org/10.1016/j.jsv.2008.05.022

56 Yu, M., Feng, N., and Hahn, E. J. Experimental evaluation of a modal parameter based system identification procedure, Mechanical Systems and Signal Processing, 68-69, 302-315, (2016). https://dx.doi.org/10.1016/j.ymssp.2015.06.024

57 Yuan, Q., Gao, R., Feng, Z., and Wang, J. Analysis of dynamic characteristics of gas turbine rotor considering contact effects and pre-tightening force, Proceedings of the ASME Turbo Expo 2008: Power for Land, Sea, and Air. Volume 5: Structures and Dynamics, 983-988, (2008). https://dx.doi.org/10.1115/GT2008-50396

${ }^{58}$ Li, Y., Liang, F., Zhou, Y., Ding, S., Du, F., Zhou, M., Bi, J., and Cai, Y. Numerical and experimental investigation on thermohydrodynamic performance of turbocharger rotor-bearing system, $A p$ plied Thermal Engineering, 121, 27-38, (2017). https://dx.doi.org/10.1016/j.applthermaleng.2017.04.041 